\title{
Mary-Rose McGuire
}

\section{Die Lizenz}

Eine Einordnung in die Systemzusammenhänge des BGB und des Zivilprozessrechts

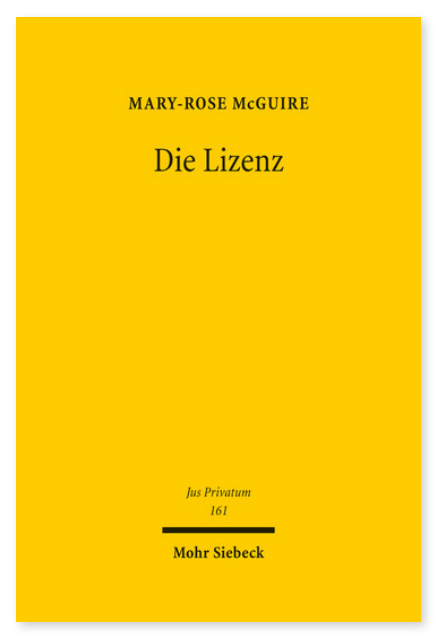

2012. XIX, 802 Seiten. JusPriv 161

ISBN 978-3-16-151878-2

DOI 10.1628/978-3-16-151878-2

eBook PDF 174,00€

ISBN 978-3-16-150425-9

Leinen $174,00 €$
Die Lizenz stellt die zentrale Verwertungsform für Rechte des Geistigen Eigentums dar. Bisher scheitert eine dogmatisch konsistente Einordnung in das Rechtssystem jedoch an der in Deutschland tradierten Abweichung vom Allgemeinen Zivilrecht sowie der starken Differenzierung nach der Art des Schutzgegenstands. Die daraus resultierenden dogmatischen Brüche und Unsicherheiten sind aus wissenschaftlicher Perspektive unbefriedigend und belasten die Vertragspraxis. Mary-Rose McGuire arbeitet die Lizenz als ein Rechtsinstitut an der Schnittstelle zwischen Allgemeinem Zivilrecht und dem Recht des Geistigen Eigentums heraus und integriert dadurch die Lizenzerteilung in das Allgemeine Zivilrecht. Die Lizenz wird als verdinglichte Obligation erfasst, der Lizenzvertrag nach dem Vorbild der Vertragstypen des BGB als einheitliches Modell konzipiert. Die Konsequenzen der Anwendung des Allgemeinen Schuldrechts werden ebenso erörtert, wie die Behandlung des Lizenzvertrags in Zwangsvollstreckungs-, Insolvenz- und Kollisionsrecht.

Mary-Rose McGuire Geboren 1974; Studium der Rechtswissenschaften an der Universität Wien; Aufbaustudium Magister des deutschen Rechts an der Universität Göttingen; wissenschaftliche Mitarbeiterin an der Universität Göttingen; 2003 Promotion.

Jetzt bestellen:

https://mohrsiebeck.com/buch/die-lizenz-9783161518782?no_cache=1

order@mohrsiebeck.com

Telefon: +49 (0)7071-923-17

Telefax: $+49(0) 7071-51104$ 